\title{
SOME REMARKS ON ISOSTASY AND THE LONG-TERM BEHAVIOR OF THE CONTINENTAL LITHOSPHERE
}

\author{
JAMES R. COCHRAN \\ Lamont-Doherty Geological Observatory of Columbia University, Palisades, NY 10964 (U.S.A.)
}

Received May 8, 1979

Revised version received September 12,1979

\begin{abstract}
The interpretation of linear transfer function (admittance) studies of the relationship between gravity anomalies and topography depends on what assumptions are made in limiting the acceptable set of solutions. However, whatever assumptions are made, the value of the flexural rigidity determined from admittance studies of Australia and the continental United States is less than about $10^{28}$ dyne-cm $(5-\mathrm{km}$ plate thickness). This is much less than values determined from other studies of the loading of continental lithosphere which consistently give values in the range of $4 \times 10^{30}$ to $2 \times 10^{31}$ dyne-cm (elastic plate thickness of $35-60 \mathrm{~km}$ ). It is argued that the latter values represent the long-term rigidity of the continental lithosphere and that the rigidity does not change greatly with age of loading.
\end{abstract}

\section{Introduction}

The concept of isostatic equilibrium dates from the discovery in the 1850's that the errors introduced into a triangulation survey of India due to changes in the deflection of the vertical (and thus of the direction in which a plumb bob hangs) caused by the mass of the Himalaya Mountains were only about onethird of what was expected. This observation was explained by Pratt [1] and Airy [2] in terms of the isostatic hypotheses which bear their names. Both of these theories state that the mass excess of the mountains is balanced or "compensated" by a mass deficiency beneath them so that at some depth within the Earth the pressure due to overlying material is a constant value. Although they differ on the nature of the compensating mass distribution, both hypotheses imply that compensation occurs locally; that is, that the compensating masses are directly beneath the topographic feature. Vening Meinesz [3-5] and Gunn [6-8] modified the Airy "floating blocks"

Lamont-Doherty Geological Observatory Contribution No. 2782. theory to take account of the strength of the lithosphere. Their method treats the lithosphere as an elastic beam or plate and the topography as a load applied to the lithosphere. Thus the lithosphere is deformed for some distance away from the topographic feature and the compensating masses are distributed over a region around the topographic feature rather than being localized directly beneath it.

The development of the concept of plate tectonics which considers the outer part of the Earth to be made up of strong, rigid plates provided a rationale for the use of the plate model of compensation and in the past several years it has been successfully applied to several features such as the outer rise off deep-sea trenches $[9,10]$ where the oceanic lithospheric plate is bent as it enters the subduction zone, sediment accumulations $[11,12]$ and seamounts [13-15] which can be considered as external loads on the lithospheric plate.

An early finding of these studies was that the lithospheric plate thickness determined from the flexural behavior of the lithosphere, which is generally in the range of $15-35 \mathrm{~km}$, is significantly less than the values of $60-100 \mathrm{~km}$ determined from 
thermal [16-18] and surface wave $[19,20]$ studies. This was originally thought by many to be an artifact of the method, and Watts and Cochran [14], for example, were careful to refer to them as "effective" plate thicknesses. However, it has become apparent that the plate thickness determined from flexural studies (elastic thickness) does have a significance and in fact represents that portion of the plate which responds in an elastic manner to a long-term load. The surface wave studies on the other hand record the response to short-term loads. Watts [21] concluded that the elastic thickness represents the depth to the $450^{\circ} \mathrm{C}$ isotherm, a suggestion that has some support from rheological studies $[22,23]$.

Recently the application of transfer function techniques developed by Dorman and Lewis [24] has led to the conclusion that the plate model of compensation can also be applied to the small-scale topography in the ocean basins which is apparently created at the mid-ocean ridges and transported away atop the oceanic lithospheric plate [25].

The transfer function technique basically assumes that the gravity anomalies are caused by topography and its compensation and attempts to determine a filter which when convolved with the topography data reproduces the gravity:

$\Delta g(x)=f(x) * t(x)$

where $g(x)$ is the gravity, $t(x)$ the topography and $f(x)$ the filter representing the response of the earth to the topography. The filter for an area can be determined in a straightforward manner from the observed gravity and topography. The transfer function technique is developed in detail by McKenzie and Bowin [25] and Watts [21].

The great advantage of this technique is that it is possible to study the state of isostasy without making any prior assumptions about how it is accomplished other than that the gravity anomalies are due to the topography and its compensation. Once determined, the transfer function or admittance can be interpreted in terms of various models of isostasy. This step, however, does involve making assumptions concerning what are acceptable density distributions. For example, the reason given by both McKenzie and Bowin [25] and Cochran [26] for ruling out local, Airy-type compensation of small-scale oceanic topography was not that it is impossible to adequately fit the observed admittances with an Airy model, but rather that to do so requires that the principal density contrasts related to the compensation be at depths of $40-50 \mathrm{~km}$. This conflicts with their assumption that the principal density contrast is at the base of the oceanic crust and led them to favor the elastic plate model.

The transfer function technique has also been applied to data from continental areas [27-29]. The remainder of this note will be concerned with the interpretation of the transfer functions determined for continental regions. There are two points which I wish to make: the first is the importance of what assumptions are made in moving from the observed admittance values to the deduced mechanism.

The second is that, whatever assumptions are made in determining the isostatic mechanism, the flexural rigidity, $D$, determined from the transfer function studies in continental regions is considerably less than that determined from flexural studies. This is a very different result from that obtained in the oceans, where the flexural rigidities (and thus elastic plate thicknesses) determined by the two methods agree quite well [21].

\section{Application of transfer function techniques to continents}

When Lewis and Dorman [27] originally determined the admittance over the continental United States, they interpreted their results in terms of local compensation involving density variations proportional to elevation and found that both positive and negative density contrasts were necessary and that compensation had to extend to a depth of $400 \mathrm{~km}$. Banks et al. [28] argued that this is not a reasonable compensation scheme and reinterpreted Lewis and Dorman's results in terms of a plate model of compensation. They concluded that permitted values of the flexural rigidity are in the range $10^{28}$ to $10^{29}$ dyne-cm corresponding to plate thicknesses in the range of 5-10 km. McNutt and Parker [29] determined the admittance for the continent of Australia and concluded that it was best explained by a plate model with a flexural rigidity of $10^{26}$ dyne-cm (equivalent to an elastic plate thickness of about 1 $\mathrm{km}$ ) and that the flexural rigidity could not be greater 
than $5 \times 10^{27}$ dyne-cm. McNutt and Parker's estimate of the flexural rigidity of Australia is one to three orders of magnitude less than that determined by
Banks et al. [28] for the United States. They explained this difference by suggesting that most of the topographic signature in the United States comes

\section{AUSTRALIA (McNutt \& Parker)}

PLATE MODEL $\left(T_{C}=32 \mathrm{~km}\right)$

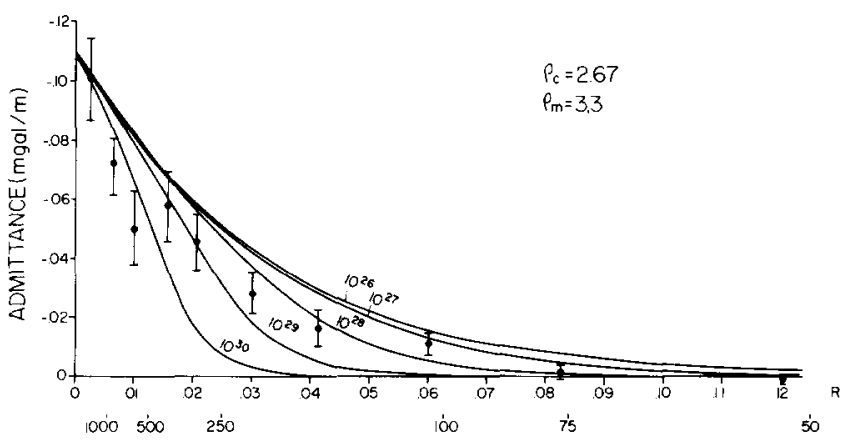

PLATE MODEL $\left(T_{C}=42 \mathrm{~km}\right)$

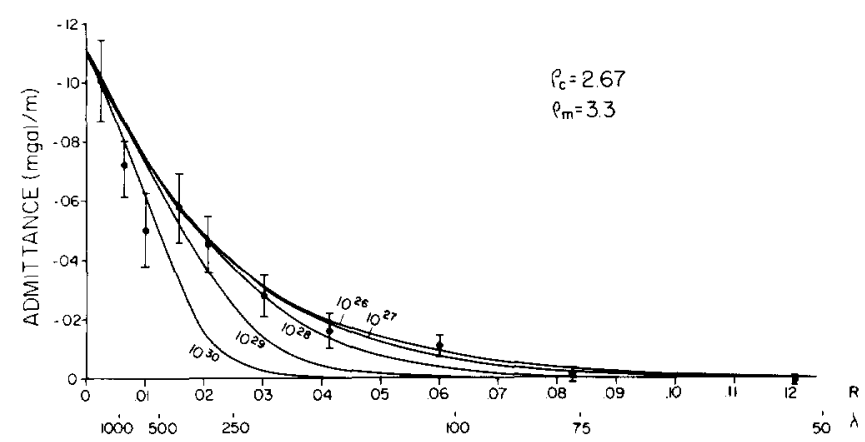

AIRY MODEL

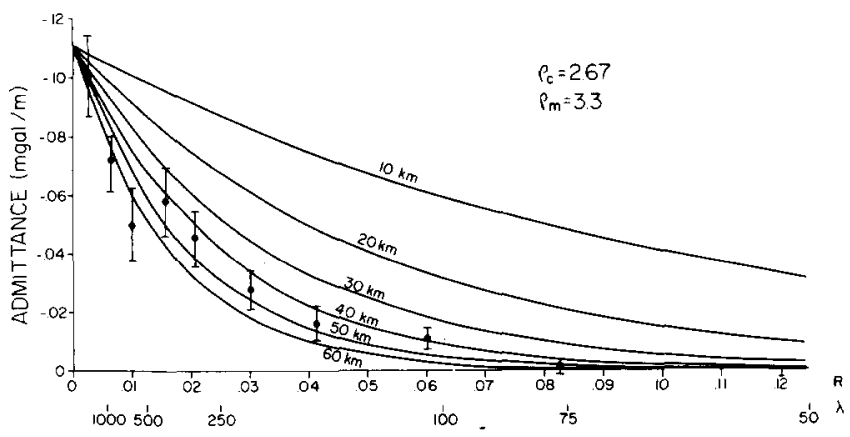

United States (Lewis \& Dorman)

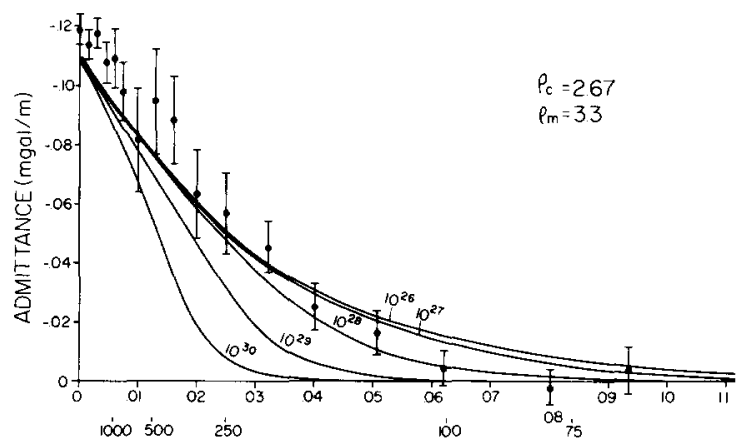

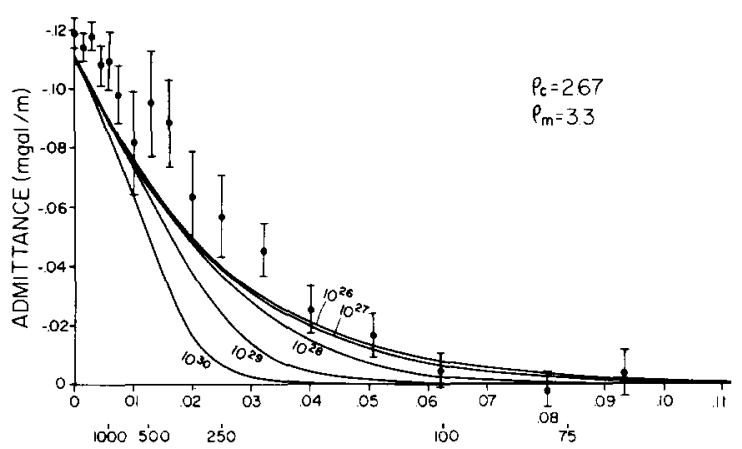

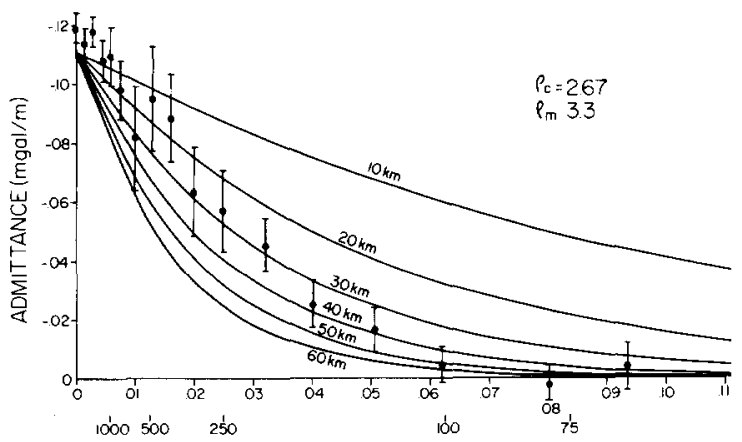

Fig. 1. Observed admittance values (dots) for Australia determined by McNutt and Parker [29] and for the United States determined by Lewis and Dorman [27]. Error bars extend one standard deviation above and below the values. Observed values are compared with theoretical admittance curves for an Airy model of isostasy and for plate models which assume crustal thicknesses of $42 \mathrm{~km}$ and $32 \mathrm{~km}$. Mathematical expressions for the theoretical curves are developed in McKenzie and Bowin [25] and Watts [21]. 
from the Rocky Mountains to which they assigned an age of about 50 m.y. while the Australian orogenies producing relief on that continent date from the Paleozoic or earlier. Thus the lower flexural rigidity which they found for Australia was ascribed to viscoelastic relaxation of the lithosphere with time after loading. They estimated the viscoelastic time constant to have a value of $4.5 \times 10^{7}$ years.

Figs. 1 and 2 show the admittance values determined from Australia by McNutt and Parker [29] and from the continental United States by Lewis and Dorman [27]. As pointed out by McNutt and Parker [29], "the two isostatic response functions evidently agree at the longest and shortest wavelengths, but in the roll-off region where wavelength $(\lambda)=500 \mathrm{~km}$, the Australian response is consistently lower" [26, p. 773]. Thus, in the wavelength range where the effects of the isostatic mechanism are manifested, a topographic feature of a given wavelength and amplitude on Australian lithosphere will have a somewhat smaller Bouguer anomaly than the same feature in the

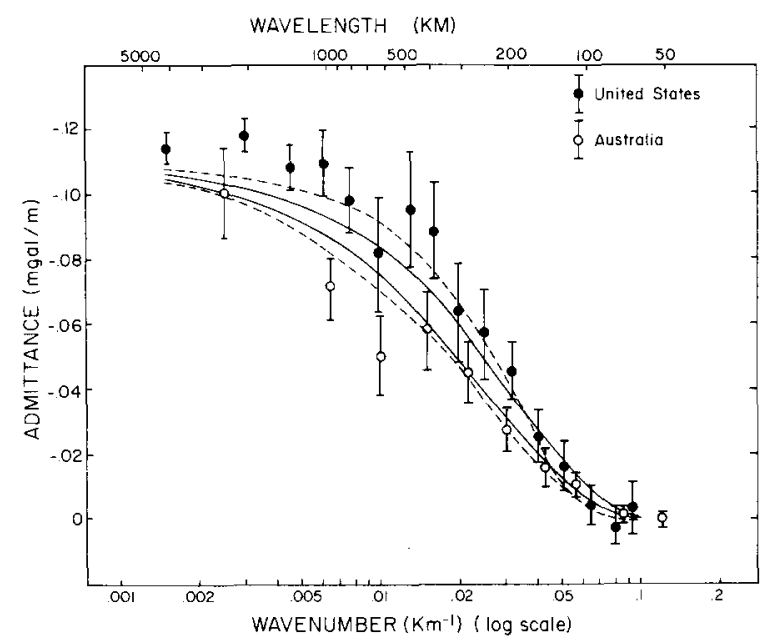

Fig. 2. Observed admittance values for Australia and for the United States plotted against wavenumber on a logarithmic scale in order to bring out the difference in curvature of the two data sets. Also shown are four theoretical admittance curves. The two dashed curves are the best-fitting models of Banks et al. [28] for the United States and McNutt and Parker [29] for Australia. The upper solid curve is that determined for a crustal thickness of $32 \mathrm{~km}$ and flexural rigidity of $2.4 \times 10^{27}$ dyne-cm. The lower solid curve is for a crustal thickness of $42 \mathrm{~km}$ and flexural rigidity of $7.1 \times 10^{26}$ dyne$\mathrm{cm}$.
United States. If the average crustal structure and thickness are similar for the two continents, this implies that the flexural rigidity of Australia is higher than that of the United States (uncompensated topography, which would have zero Bouguer anomaly, in effect represents infinite flexural rigidity).

For example, if an average crustal thickness of 42 $\mathrm{km}$, the value which McNutt and Parker found best fits the Australian data, and is about the average crustal thickness in Australia [30-34] is assumed, with the density contrasts giving rise to the Bouguer anomalies assumed to be at the base of the crust, then the best fitting elastic plate thickness in a least squares sense is $2 \mathrm{~km}\left(D=7.1 \times 10^{26}\right.$ dyne-cm) for Australia and $1 \mathrm{~km}\left(D=8.9 \times 10^{25}\right.$ dyne-cm) for the United States. If a smaller crustal thickness of $32 \mathrm{~km}$ is chosen, then the best-fitting plate thicknesses are 7 $\mathrm{km}\left(D=3 \times 10^{28}\right.$ dyne-cm $)$ for Australia and $3 \mathrm{~km}$ $\left(D=2.4 \times 10^{27}\right.$ dyne-cm) for the United States. Thus, as argued above, for similar density structures, the Australian data requires a slightly higher flexural rigidity than does the United States data. Even if crustal thicknesses of $42 \mathrm{~km}$ for Australia and $32 \mathrm{~km}$ for the United States are assumed, then the effective flexural rigidity of the two continents is similar. Also, as the density contrasts producing the Bouguer gravity anomalies are brought to shallower depths, the best-fitting effective flexural rigidity increases. Theoretical admittance curves for crustal thicknesses of $42 \mathrm{~km}$ and $32 \mathrm{~km}$ assuming an elastic plate model and also a set of curves assuming a local Airy-type compensation model are superimposed on the observed admittance values in Fig. 1. The above line of reasoning results in a conclusion which is the reverse of that reached by McNutt and Parker [29]. The reason for this is a difference in what was adopted as constraints on acceptable solutions. In the above discussion, I assumed that the major density contrast responsible for the Bouguer anomalies occurs at the base of the crust and found the best-fitting flexural rigidity when a reasonable range of crustal thicknesses are assumed.

Banks et al. [28] and McNutt and Parker [29] on the other hand, were more concerned with the shape of the admittance curve. There is a distinct difference in the curvature of the admittance values for the continental United States and for Australia. This can easily be seen in Fig. 2 where the values for the two 
continents are plotted against the logarithm of the wavenumber. The greater curvature of the admittance for the United States in the 200- to $1000-\mathrm{km}$ wavelength range indicates, other parameters being the same, that compensation is more regional (the flexural rigidity is higher) in the United States than Australia. Thus by being concerned with matching the curvature, Banks et al. [28] were able to obtain a better fit to the admittance curve than I was able to in the examples given above. However, to do this, they had to put the principal density contrast giving rise to the Bouguer anomalies in the United States not at the base of the crust, but well up within it. When both the crustal thickness and plate thickness were allowed to vary, I obtained best-fitting values of $16 \mathrm{~km}$ for the crustal thickness and $7 \mathrm{~km}$ for the effective elastic plate thickness.

Thus, the conclusions arrived at in this type of study depend critically on the parameter which is taken as governing the acceptable set of solutions. The noise inherent in including data from an entire continent, with different tectonic provinces, ages and densities, is probably great enough that a plausible case could be made for either of the above lines of reasoning.

\section{Isostatic relations on the continents}

Whatever assumptions are made for the density structure beneath the continents, a principal result of the transfer function studies on the Australian and North American continents is that the flexural rigidity, $D$, determined by that method is relatively low, less than about $10^{28}$ dyne-cm.

The admittance values for such low rigidities are not significantly different from those for the Airy model. The admittance curves for flexural rigidities of $10^{26}$ dyne-cm and less are indistinguishable from that for the Airy case and the differences do not start to become significant until the rigidity is of the order of about $10^{27}$ to $10^{28}$ dyne-cm. Thus McNutt and Parker [29] found that their data were adequately fit for values of $D$ from zero to $5 \times 10^{27}$ dyne-cm with almost the same misfit over that entire range.

Let us now consider determinations of the flexural rigidity of continental areas made by other methods. Table 1 gives eight determinations of the flexural rigidity of continental lithosphere. The first three, the Caribou Mountains, Interior Plains and Boothia Uplift are from Walcott [13]. I have not included three other determinations by Walcott [13] from lakes formed by the melting of the Pleistocene continental ice sheets because the short time for which the loads were present may not have allowed an equilibrium situation to be reached. I also consider the Boothia Uplift value to be questionable. It was determined from the width of a horst which was interpreted by Walcott [13] as resulting from stresses within the lithosphere due to the flexure caused by differential loading of an originally small basement irregularity. Actually uplift of the Boothia Arch occurred in several distinct episodes between late Precambrian and Devonian time with long intervening quiescent periods during at least some of which it appears to have been completely covered over by sediments $[35,36]$. It is not obvious how this history can be related to lithospheric flexure. All of the values of the flexural rigidity from Walcott [13] have been increased by a factor of 4 due to an error in their determination pointed out by Walcott [40].

The value for northern India was obtained by Molnar et al. [37] by observing that the Indian plate is bent under the Asian plate north of the Ganga Basin and considering the Central Indian Plateau as the equivalent of the outer rise of deep-sea trenches.

The Michigan Basin value was arrived at by Haxby et al. [38] by considering the distribution and thickness of sediments deposited in the basin during various time intervals. They found that the effective flexural rigidity appeared to increase with time which was ascribed to cooling of the lithosphere following penetration of a hot asthenospheric diapir to near the base of the crust initiating subsidence in the basin.

The final determination is by Cohen and Meyer [39] from a seismic study which yielded a profile of the shape of the Moho across the Mid-Continent gravity high.

These flexural rigidity determinations are plotted against $\log _{10}$ of the time of loading in Fig. 3. The value determined by Walcott [13] for the Boothia Uplift is shown as a dashed box since I consider it to be questionable. It is quite clear from Fig. 3 that the estimates of the flexural rigidity from the admittance studies are much less than those determined by other means. However, when comparing values of the flex- 
TABLE 1

Determinations of flexural rigidity in continental regions

\begin{tabular}{|c|c|c|c|c|}
\hline Location & $\begin{array}{l}\text { Flexural rigidity } \\
\text { (dyne-cm) }\end{array}$ & Method & $\begin{array}{l}\text { Estimated age of loading } \\
\text { (years) }\end{array}$ & Reference \\
\hline 1. Caribou Mountains & $1.2 \times 10^{31}$ & deformation study & $10^{6}-10^{7}$ & {$[13]$} \\
\hline 2. Interior Plains & $1.6 \times 10^{31}$ & minimizing isostatic anomalies & $10^{6}-10^{7}$ & [13] \\
\hline 3. Boothia Uplift? & $1.1 \times 10^{31}$ & deformation study & $5 \times 10^{8}$ & [13] \\
\hline 4. Michigan Basin & $4.8 \times 10^{30}$ & $\begin{array}{l}\text { deformation study (shape of } \\
\text { sediment surfaces) }\end{array}$ & $5 \times 10^{8}$ & [38] \\
\hline 5. Northern India & $3.75 \times 10^{31}$ & deformation study & $<4 \times 10^{7}$ & {$[37]$} \\
\hline 6. Mid-Continent gravity high & $4 \times 10^{30}$ & shape of Moho & $1.1 \times 10^{9}$ & [39] \\
\hline \multirow[t]{2}{*}{ 7. Continental United States } & $10^{28}-10^{29}$ & linear transfer function & $5 \times 10^{7}$ & [28] \\
\hline & $<5 \times 10^{27}$ & & & this study \\
\hline 8. Australia & $<5 \times 10^{27}$ & linear transfer function & $>2 \times 10^{8}$ & [29] \\
\hline
\end{tabular}

? This determination is considered doubtful as noted in text.

ural rigidity it must be remembered that, on a viscoelastic earth, the change in time of the effective flexural rigidity is a function of the wavelength of the load. Thus, as can be seen in Fig. 4, features of different wavelength which load a lithosphere of a given initial flexural rigidity will show differing effective flexural rigidities at some later time with the longer wavelength features indicating a lower value.

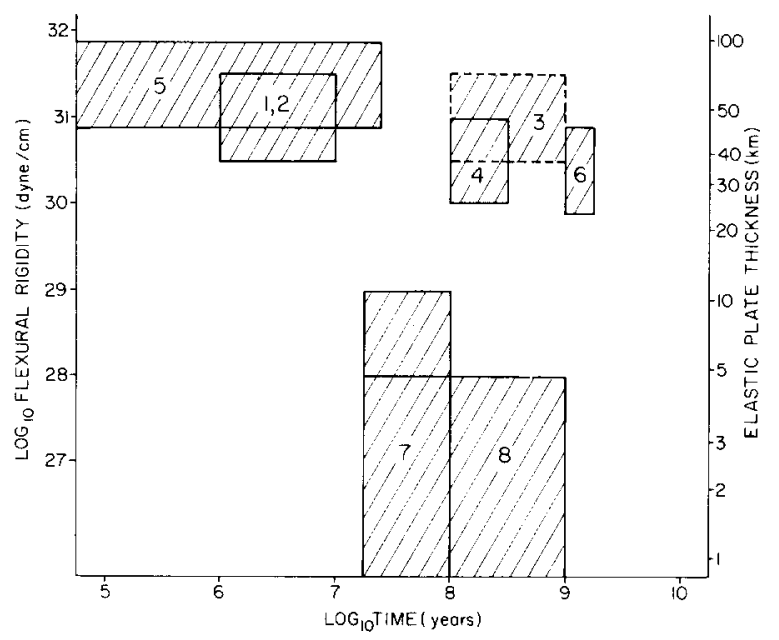

Fig. 3. Determinations of the flexural rigidity of continents plotted against $\log _{10}$ of the time of loading. Numbers correspond to those in Table 1 identifying the estimates. The Boothia uplift value (box 3 ) is dashed since it is considered to be unreliable.
McNutt and Parker [29] argue that most of the topographic energy comes from the mountain ranges in the two continents so that their results are appropriate to those regions. The Great Dividing Range in Australia is a linear feature with a dominant wavelength of $500-600 \mathrm{~km} \mathrm{[41].} \mathrm{The} \mathrm{individual} \mathrm{ranges}$ making up the Cordilleran system in the western United States are of the order of $100 \mathrm{~km}$ across $(\lambda=$ $200 \mathrm{~km}$ ).

Another linear feature among those listed in

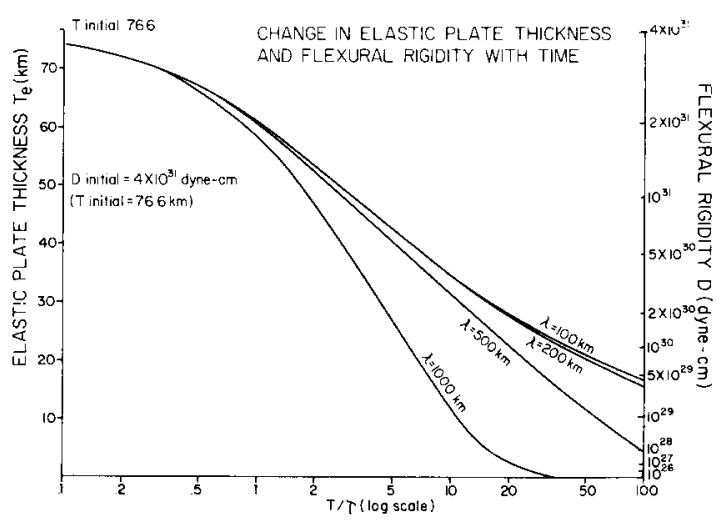

Fig. 4. Change in time of the effective elastic plate thickness and flexural rigidity of a viscoelastic plate for sinusoidal loads of various wavelengths following development of Walcott [40]. Time is expressed as a fraction of the viscoelastic time constant $\tau$. The initial flexural rigidity is $4 \times 10^{31}$ dyne-cm corresponding to an initial plate thickness of $76.6 \mathrm{~km}$. 
Table 1 is the Mid-Continent gravity high which has a width of $60-100 \mathrm{~km}$ meaning that it can be assigned a wavelength of $120-200 \mathrm{~km}$. It is associated with Keweenawan basaltic flows and intrusive gabbros which were emplaced between 1120 and $1140 \mathrm{~m} . y$. B.P. $[42,43]$. The flexural rigidity of $4 \times 10^{30}$ dyne-cm determined by Cohen and Meyer [39] implies an elastic plate thickness of about 35 $\mathrm{km}$. Referring to Fig. 4 , it can be seen that for that particular choice of an initial flexural rigidity, $4 \times 10^{31}$ dyne-cm, corresponding to an elastic plate thickness of $76.6 \mathrm{~km}$, the 100 - and $200-\mathrm{km}$ curves pass through $4 \times 10^{30}$ dyne-cm at a value of $t / \tau$ of about 10 . Considering the age of the rocks responsible for the Mid-Continent gravity high, this is con-sistent with the value of $10^{8}$ years suggested for $\tau$ by McNutt and Parker [29]. However, the transfer function study values for Australia and the continental United States cannot be explained by this particular set of parameters unless they are dominated by wavelengths of greater than $1000 \mathrm{~km}$ or associated with ages that are considerably greater than 1000 m.y. In fact it has not been possible to find a combination of initial plate thickness and viscoelastic time constants capable of explaining the data shown in Table 1 and Fig. 3.

A rheological model for the lithosphere perhaps can be found which is consistent with the data. However, a simple explanation is available from the observation that, with the exception of the values from the admittance studies, the estimates of the flexural rigidity cluster in the range of about $4 \times 10^{30}$ to $2 \times 10^{31}$ dyne-cm (equivalent to elastic plate thicknesses of $35-60 \mathrm{~km}$ ). We suggest that the normal elastic thickness of continental lithosphere is in this range and that it either does not change with time after loading or does so with such a large time constant $\left(>10^{9}\right.$ years) that the flexural rigidity can essentially be considered constant over geologic history.

The reason for preferring the flexural rigidity determinations from individual features to the continent-wide transfer function studies is just that they are from studies of individual features and thus we can be certain that the results are pertinent to that feature and are not confused by the inclusion of data from areas of greatly different ages, composition and history. Also the determinations were made by a number of methods which gave similar results.

The low values obtained in the continent-wide transfer function studies must therefore be measuring a different signal. If we accept McNutt and Parker's [29] suggestion that the main contribution to the continental admittance comes from mountain ranges where the topographic relief is greatest, then an explanation can be found for these low values. Mountain ranges are formed on the borders of the continental cratonic blocks under temperature and pressure conditions quite different from those found in stable interior regions. Consideration of the forces involved in the formation of the Appalachian Mountains led Rodgers [45] to use the analogy of a monstrous vise. Under such circumstances, it is probably not valid to use the model of the topography of the mountains as a load on an elastic or viscoelastic lithosphere when discussing isostasy at orogenic belts.

The crust under Central Europe increases in thickness from about $35 \mathrm{~km}$ near Munich in southern Germany to $55-60 \mathrm{~km}$ under the axis of the Alps [46]. Compressional tectonics in the Alps began in the Cretaceous, reached a climax in the Oligocene and lasted in to the Pliocene [47]. Since the Pliocene, although there has been considerable local subsidence in the sediment-filled molasse troughs flanking the range the main movement has been uplift which is responsible for most of the present relief [48]. This is exactly the opposite of what might be expected if a "root" was forming through viscoelastic relaxation of the lithosphere. Thus the thick crustal "root" which provides a majority of the compensation for the gross elevation appears to have formed nearly contemporaneously with the mountain range under conditions which resulted in a situation approaching Airy isostasy. The main vertical motion found at most Phanerozoic mountain belts is uplift, apparently in isostatic adjustment to erosion of the topographic relief.

Another possibility is, of course, that the low rigidities obtained from the continent-wide studies result from the extreme complexity of the continental crust and lithosphere and that it is not really possible to develop a transfer function which can adequately describe the relationship between gravity and topography on a continent-wide basis. For example, the transfer function for the United States [27] includes data from the tectonically active basin 
and range province and from more stable cratonic regions. Also the complex history and structure of continental regions results in gravity anomalies that are not simply related to topography and its compensation as is assumed by the transfer function technique. A prominent example is in Australia where the most striking feature on the Bouguer gravity map [44], a series of large amplitude east-west-trending highs and lows through the center of the continent, are not obviously related to surface relief.

\section{Conclusions}

There are two points that I have attempted to make in this note.

(1) Transfer function or admittance techniques, although providing a direct measurement of the relationship between gravity anomalies and topography, do not remove the ambiguity inherent in deducing structure from gravity anomalies. Thus, in using these techniques to study the isostatic mechanism, the results depend critically on what assumption is used to limit the acceptable set of solutions. Thus, entirely different conclusions can be reached depending on which of two approaches is taken, either of which might be considered reasonable. Thus, it is necessary to clearly state what assumptions go into an analysis and what implications the result that comes out has for parameters such as crustal thickness.

(2) The estimates of the flexural rigidity obtained by continent wide admittance studies of the United States and of Australia are considerably less than those obtained from studies of individual features by a number of methods.

I conclude that the studies of individual features probably give a better estimate of the continental flexural rigidity. They imply that it is in the range of about $4 \times 10^{30}$ to $2 \times 10^{31}$ dyne-cm. These values correspond to effective elastic plate thicknesses of $35-60 \mathrm{~km}$. There is no evidence that the flexural rigidity decreases significantly over time spans of a billion years.

It is possible that the low values determined by the admittance studies result from their being dominated by the larger-scale topography which is compensated in what nearly amounts to a local Airy-type manner. This, in turn is the result of the fact that this large- scale topography was not formed in the interior of a plate, but rather at a plate margin under rather severe conditions.

\section{Acknowledgements}

I would like to thank M.E. Chapman, S.T. Crough, R.S. Detrick, W.F. Haxby, M.K. McNutt, and A.B. Watts for constructive criticism. This work was supported by National Science Foundation grant OCE77-07941 and Office of Naval Research contract N00014-75-C-0210.

\section{References}

1 J.H. Pratt, On the attraction of the Himalaya Mountains and of the elevated regions beyond them, upon the plumb line in India, Philos. Trans. Roy. Soc. 145 (1855) $53-100$.

2 G.B. Airy, On the computation of the effect of the attraction of mountain-masses, as disturbing the apparent astronomical latitude of stations of geodetic surveys, Philos. Trans. Roy. Soc. 145 (1855) 101-104.

3 F.A. Vening Meinesz, Une nouvelle méthode pour la réduction isostatique régionale de l'intensité de la pesanteur, Bull. Géod. 29 (1931) 33-51.

4 F.A. Vening Meinesz, Tables fondamentales pour la réduction isostatique régionale, Bull. Géod. 63 (1939).

5 F.A. Vening Meinesz, Tables for regional and local isostatic reduction (Airy system) for gravity values, Publ. Neth. Geod. Comm. (Waltman, Delft, 1941).

6 R. Gunn, A quantitative study of the influence of the lithosphere on the anomalies of gravity, Franklin Inst. J. 236 (1943) 47--65.

7 R. Gunn, A quantitative study of the lithosphere and gravity anomalies along the Atlantic coast, Franklin Inst. J. 237 (1944) 139-154.

8 R. Gunn, Isostasy Extended, J. Geol. 57 (1949) 263 279.

9 T.C. Hanks, The Kuril trench-Hokkaido rise system: large shallow earthquakes and simple models of deformation, Geophys. J. R. Astron. Soc. 23 (1971) 173-189.

10 A.B. Watts and M. Talwani, Gravity anomalies seaward of deep-sea trenches and their tectonic implications, Geophys. J. R. Astron. Soc. 36 (1974) 57-90.

11 R. Walcott, Gravity, flexure and the growth of sedimentary basins at a continental edge, Geol. Soc. Am. Bull. 83 (1972) 1845-1848.

12 J.R. Cochran, Gravity and magnetic investigations in the Guiana Basin, western equatorial Atlantic, Geol. Soc. Am. Bull. 84 (1973) 3249-3268.

13 R.I. Walcott, Flexural rigidity, thickness, and viscosity of the lithosphere, J. Geophys. Res. 75 (1970) 3941-3954. 
14 A.B. Watts and J.R. Cochran, Gravity anomalies and flexure of the lithosphere along the Hawaiian-Emperor Seamount Chain, Geophys. J. R. Astron. Soc. 38 (1974) 119-141.

15 A.B. Watts, J.R. Cochran and G. Selzer, Gravity anomalies and flexure of the lithosphere: a three-dimensional study of the Great Meteor Seamount, northeast Atlantic, J. Geophys. Res. 80 (1975) 1391-1398.

16 D.P. McKenzie, Some remarks on heat flow and gravity anomalies, J. Geophys. Res. 72 (1967) 6261-6273.

17 J.G. Sclater and J. Francheteau, The implications of terrestrial heat-flow observations on current tectonic and geochemical models of the crust and upper mantle of the earth, Geophys. J. R. Astron. Soc. 20 (1970) 509-542.

18 R.L. Parker and D.W. Oldenburg, A thermal model of oceanic ridges, Nature 242 (1973) 137-139.

19 D.W. Forsy th, The early structural evolution and anistrophy of the oceanic upper mantle, Geophys. J. R. Astron. Soc. 43 (1975) 103-162.

20 A.R. Leeds, Lithospheric thickness in the western Pacific, Phys. Earth Planet. Inter. 11 (1975) 61-64.

21 A.B. Watts, An analysis of isostasy in the world's oceans, 1. Hawaiian-Emperor seamount chain, J. Geophys. Res. 83 (1978) 5989-6004.

22 D.L. Anderson and J.B. Minster, Seismic velocity, attenuation and rheology of the upper mantle, Phys. Earth Planet. Inter. (in press).

23 J.H. Bodine, M.S. Steckler and A.B. Watts, Observations of flexure and the rheology of the oceanic lithosphere, Trans. Am. Geophys. Union 60 (1979) 393 (abstract).

24 L.M. Dorman and B.T.R. Lewis, Experimental isostasy, 1. Theory of the determination of the Earth's isostatic response to a concentrated load, J. Geophys. Res. 75 (1970) 3357-3365.

25 D.P. McKenzie and C.O. Bowin, The relationship between bathymetry and gravity in the Atlantic Ocean, J. Geophys. Res. 81 (1976) 1903-1915.

26 J.R. Cochran, An analysis of Isostasy in the world's oceans, 2. Mid-ocean ridge crests, J. Geophys. Res. (in press).

27 B.T.R. Lewis and L.M. Dorman, Experimental isostasy, 2. An isostatic model for the U.S.A. derived from gravity and topographic data, J. Geophys. Res. 75 (1970) 33673386.

28 R.J. Banks, R.L. Parker and S.P. Huestis, Isostatic compensation on a continental scale: local versus regional mechanisms, Geophys. J. R. Astron. Soc. 51 (1977) 431-452.

29 M.K. McNutt and R.L. Parker, Isostasy in Australia and the evolution of the compensation mechanism, Science 199 (1978) 773-775.

30 B.A. Bolt, H.A. Doyle and D.J. Sutton, Seismic observations from the 1956 atomic explosions in Australia, Geophys. J. R. Astron. Soc. 1 (1958) 135-145.

31 H.H. Doyle and I.B. Everingham, Seismic velocities and crustal structure in southern Australia, J. Geol. Soc. Aust. 11 (1964) 141-150.
32 D.M. Finlayson, First arrival data from the Carpentaria Region Upper Mantle Project (CRUMP) J. Geol. Soc. Aust. 15 (1968) 33-50.

33 D. Denham, D.W. Simpson, P.J. Gregson and D.J. Sutton, Travel times and amplitudes from explosions in northern Australia, Geophys. J. R. Astron. Soc. 28 (1972) $225-235$.

34 S.P. Mathur, F.J. Moss and J.G. Bransen, Seismic and gravity investigations along the geotraverse, western Australia, 1965, Bur. Miner. Resour. Geol. Geophys. Bull. 191 (1977) $63 \mathrm{pp}$.

35 J.W. Kerr and R.L. Christie, Tectonic history of Boothia Uplift and Cornwallis Fold Belt, Arctic Canada, Bull. Am. Assoc. Pet. Geol. 49 (1965) 905-926.

36 R.L. Brown, I.W.D. Dalziel and B.R. Rust, The structure, metamorphism and development of the Boothia Arch, Arctic Canada, Can. J. Earth Sci. 6 (1969) 525-543.

37 P. Molnar, W.P. Chen, T.J. Fitch, P. Tapponnier, W.E.K. Warsi and F.T. Wu, Structure and tectonics of the Himalaya: a brief summary of relevant geophysical observations, C.N.R.S. Colloq. on the Himalaya (in press).

38 W.F. Haxby, D.L. Turcotte and J.M. Bird, Thermal and mechanical evolution of the Michigan Basin, Tectonophysics 36 (1976) 57-75.

39 T.J. Cohen and R.P. Meyer, The Mid-Continent gravity high: gross crustal structure, in: The Earth Beneath the Continents, J.S. Steinhardt and T.J. Smith, eds., Am. Geophys. Union, Geophys. Monogr. 10 (1966) 141-165

40 R.I. Walcott, Lithospheric flexure, analysis of gravity anomalies and the propagation of seamount chains, in: The Geophysics of the Pacific Ocean Basin and its Margin, G.H. Sutton, M.H. Manghnani and R. Moberly, eds., Am. Geophys. Union, Geophys. Monogr. 19 (1976) 431 438.

41 T.W.E. David, The Geology of the Commonwealth of Australia, Vol. 2, (E. Arnold, London, 1950) 618 pp.

42 L.T. Silver and J.C. Green, Time constants for Keweenawan igneous activity, Geol. Soc. Am. Abstr. Progr. 4 (1972) 665 (abstract)

43 C.G. Chase and T.H. Gilmer, Precambrian plate tectonics: the Mid-Continent gravity high, Earth Planet. Sci. Lett. 21 (1973) 70-78.

44 Bureau of Mineral Resources, Geology and Geophysics, Gravity Map of Australia (Canberra, A.C.T., 1976).

45 J. Rodgers, The Tectonics of the Appalachians (WileyInterscience, New York, N.Y., 1970) 271 pp.

46 P. Giese and C. Prodehl, Main features of crustal structure in the Alps, in: Explosion Seismology in Central Europe: Data and Results, P. Giese, C. Prodehl and A. Stein, eds. (Springer-Verlag, Berlin, 1976) 347-376.

47 J.G.C. Anderson, The Structure of Western Europe (Pergamon Press, Oxford, 1978) 249 pp.

48 R. Trümpy, Paleotectonic evolution of the central and western Alps, Geol. Soc. Am. Bull. 71 (1960) 843-908. 